OPEN ACCESS

Edited by:

Miguel Ferrer,

Spanish National Research

Council, Spain

Reviewed by:

Christopher Wolf,

Oregon State University, United States Emiliano Mori,

University of Siena, Italy

*Correspondence:

Veronica Nanni

veronicananni7@gmail.com

Specialty section:

This article was submitted to

Conservation,

a section of the journal

Frontiers in Ecology and Evolution

Received: 24 July 2019 Accepted: 04 March 2020 Published: 24 March 2020

Citation:

Nanni V, Caprio E, Bombieri G Schiaparelli S, Chiorri C, Mammola S,

Pedrini $P$ and Penteriani V (2020)

Social Media and Large Carnivores:

Sharing Biased News on Attacks on

Humans. Front. Ecol. Evol. 8:71

doi: 10.3389/fevo.2020.00071

\section{Social Media and Large Carnivores: Sharing Biased News on Attacks on Humans}

\author{
Veronica Nanni ${ }^{1,2 *}$, Enrico Caprio ${ }^{3}$, Giulia Bombieri ${ }^{2,4}$, Stefano Schiaparelli ${ }^{1,5}$, \\ Carlo Chiorri ${ }^{6}$, Stefano Mammola ${ }^{7,8}$, Paolo Pedrini ${ }^{4}$ and Vincenzo Penteriani ${ }^{2}$
}

${ }^{1}$ Department of Earth, Environmental and Life Science (DISTAV), University of Genoa, Genova, Italy, ${ }^{2}$ Research Unit of Biodiversity (UMIB, CSIC-UO-PA), Mieres, Spain, ${ }^{3}$ Department of Life Science and Systems Biology, University of Torino, Turin, Italy, ${ }^{4}$ MUSE - Science Museum, Vertebrate Zoology Section, Trento, Italy, ${ }^{5}$ Italian National Antarctic Museum (MNA, Section of Genoa), University of Genoa, Genova, Italy, ${ }^{6}$ Department of Educational Sciences, University of Genoa, Genova, Italy, ${ }^{7}$ LIBRe - Laboratory for Integrative Biodiversity Research, Finnish Museum of Natural History, University of Helsinki, Helsinki, Finland, ${ }^{8}$ Molecular Ecology Group (MEG), Water Research Institute, National Research Council of Italy (CNR-IRSA), Verbania, Italy

The Internet and social media have profoundly changed the way the public receives and transmits news. The ability of the web to quickly disperse information both geographically and temporally allows social media to reach a much wider audience compared to traditional mass media. A powerful role is played by sharing, as millions of people routinely share news on social media platforms, influencing each other by transmitting their mood and feelings to others through emotional contagion. Thus, social media has become crucial in driving public perception and opinion. Humans have an instinctive fear of large carnivores, but such a negative attitude may be amplified by news media presentations and their diffusion on social media. Here, we investigated how reports of predator attacks on humans published in online newspapers spread on social media. By means of multi-model inference, we explored the contribution of four factors in driving the number of total shares (NTS) of news reports on social media: the graphic/sensationalistic content, the presence of images, the species, as well as the newspaper coverage. According to our results, the information delivered by social media is highly biased toward a graphic/sensationalistic view of predators. Thus, such negative coverage might lead to an unjustified and amplified fear in the public with consequent lower tolerance toward predators and decrease in the support for conservation plans. However, because social media represents a powerful communication tool, its role might be reversed to positive if used appropriately. Thus, constant engagement of scientists on social media would be needed to both disseminate more accurate information on large carnivores and stem the tide of misinformation before its widespread diffusion, a crucial step for effective predator conservation.

Keywords: emotional contagion, human-wildlife conflict, media reports, attacks on humans, Twitter, Facebook, sensationalism 
"If searching for news was the most important development of the last decade, sharing news may be among the most important of the next"

(Olmstead et al., 2011).

\section{INTRODUCTION}

The Internet and social media (SM) such as Facebook and Twitter have profoundly changed the way the public receives and transmits news. The ability of the web to quickly disperse information both geographically and temporally allows SM to reach a much wider audience compared to traditional mass media (Papworth et al., 2015), and even very localized events can be broadcast worldwide. Moreover, the effect of making news available anytime and anywhere has been strengthened by the ascent of smartphones and mobile connectivity (Purcell et al., 2010; Couldry, 2012), and the omnipresent virtual world is emerging as a prevalent and easy-access source of news reports (Olmstead et al., 2011).

By becoming involved in the process of spreading news, the general public has been converted from passive reader to active producer (Nov et al., 2010; Szabo and Huberman, 2010; Rutsaert et al., 2013). People can now actively personalize, filter, and react to reports, turning the news into a social experience (Purcell et al., 2010). As a consequence, society is undergoing a real revolution based on this novel communication landscape, in which media companies, firms, and many other organizations have embraced SM to keep close ties with their audience (Kietzmann et al., 2011; Hermida et al., 2012; Osatuyi, 2013). Today, most newspapers not only own a website, but also a page on one or more SM platforms, where they can publish and spread their news reports extremely fast (Farhi, 2009; Hermida et al., 2012; Ju et al., 2014).

In this context, a powerful role is played by internet sharing. Indeed, millions of people routinely share news on SM platforms (Purcell et al., 2010), which has become crucial in supporting news production and diffusion (Lee and Ma, 2012), but also in driving public opinion (Olmstead et al., 2011). When sharing content, people can influence each other by transmitting their mood and feelings to others through emotional contagion (Bösch et al., 2018) and, in this sense, SM has the potential power to generate a massive-scale contagion (Kramer et al., 2014). An et al. (2011) highlighted the power of social recommendation, which significantly increases the audience of media sources. Furthermore, it has been shown that, when newspaper content is characterized by awe, anxiety, and anger, it is positively linked to online virality (Berger and Milkman, 2012) and that emotionally charged tweets are retweeted more quickly and more often than neutral ones (Stieglitz and Dang-Xuan, 2013).

Human-large carnivore conflict is the major barrier to the conservation of these species and attacks on humans represent the most extreme form of such conflict. It is well-recognized that human acceptance of large carnivores plays a crucial role in the fate of these species (Ripple et al., 2014) and acceptance highly depends on the real or perceived risk that these species pose to human safety (Decker et al., 2002; Knopff et al., 2016). Thus,

Abbreviations: SM, Social Media; NTS, Number of Total Shares. violent and sensationalistic content (so-called graphic content), may increase predator risk perception leaving the public gripped by unwarranted fear (Altheide, 1997; Zillmann et al., 2004; Schafer, 2011; Bornatowski et al., 2019), thus exacerbating human conflict with these species.

In modern times, predator attacks on humans are rare events but they are often overplayed by the media (Penteriani et al., 2016). A single attack may be reported by dozens of different newspapers, causing the public to be inundated with such information and, consequently, to overestimate the frequency of and increase concerns for such statistically low-risk events (Sunstein, 2002). People form their perception of risk by relying on the information conveyed by the media rather than on direct personal experience, and media reports can lead to a social amplification or attenuation of risk according to the way in which the events are framed (Kasperson and Kasperson, 1996; Schafer, 2011). For example, almost half of the media reports describing predator attacks on humans published in international newspapers include graphic content, which may lead to amplifying the fear of predators in the public (Bombieri et al., 2018). Because of SM, such graphic reports now have the potential to be quickly shared and spread by readers all around the world, increasing the negative impact of graphic information through emotional contagion (Kramer et al., 2014; Ferrara and Yang, 2015). In addition, spreading and amplifying negative messages about predators through SM could eventually cause the failure of coexistence efforts implemented by conservation policies (Bornatowski et al., 2019). Additionally, according to Papworth et al. (2015), the presence of illustrations in online news reports significantly increases their likelihood of being shared or liked on Facebook and Twitter, as were reports focused on charismatic mammals. Wu et al. (2018) also found that a larger number of pictures was associated with a higher readership count.

Here, we investigated how reports on predator attacks on humans published in online newspapers spread on SM. Specifically, we hypothesized that: (1) reports containing graphic information are more frequently shared on SM than non-graphic reports; (2) reports containing images are more frequently shared than reports with no images; (3) the number of total shares (NTS, i.e., number of times a report was shared on SM) varies according to the species considered; and (4) a wider newspaper audience corresponds to a higher NTS on SM.

\section{METHODS}

Here we updated the dataset used by Bombieri et al. (2018 $n$ $=1,584$ media reports published between January 2005 and July 2016), by searching for media reports on large carnivore attacks on humans published online from August 2016 to December 2017 and by recording new variables. The final database contained 1,774 reports on large carnivore attacks on humans.

The reports concerned attacks by 10 terrestrial predator species, i.e., gray wolf (Canis lupus Linnaeus, 1758), coyote (C. latrans Say, 1823), cougar [Puma concolor (Linnaeus, 1771)], lion 
(Panthera leo Linnaeus, 1758), tiger (P. tigris Linnaeus, 1758), leopard ( $P$. pardus Linnaeus, 1758), both Eurasian and North American brown bear/grizzly (Ursus arctos arctos Linnaeus, 1758 and $U$. a. horribilis Ord, 1815), black bear (U. americanus Pallas, 1780) polar bear (U. maritimus Phipps, 1774), and sloth bear (Melursus ursinus Shaw, 1791), as well as 3 generic aquatic predator taxa, i.e., "sharks," "crocodiles" and "alligators." In fact, for the latter groups, the exact species was not mentioned in the majority of newspapers. However, in the case of alligators, thanks to the information on the geographical area in which the attacks occurred, we were able to identify the species, i.e., the American alligator [Alligator mississippiensis (Daudin, 1801)] as it is the only one living in that region.

The report search was conducted on Google by using a combination of the 13 different species or taxa and the word "attack" followed by one of the years between 2005 and 2017 (e.g., "lion attack 2005" or "shark attack 2017"), determined a total of 169 keyword combinations (i.e., 10 species/taxa x 13 years). To simulate people's news searches on the internet, we collected attack news on the first five pages of Google (when no more articles on attacks were shown) or up to the 10th Google page if news reports about attacks on humans were still present on the fifth page.

For each report we recorded the NTS on social media (e.g., Facebook, Twitter, G+, Reddit, Pinterest) as shown on the report webpage. This information was collected from January to March 2018. We considered this approach to be reliable given that, on average, the NTS of reports on SM reach a plateau after 30 days from their online publication (Papworth et al., 2015). When the NTS on social media exceeded 999, the reports' webpage did not show the exact number, but instead reported a range (e.g., 1,000-1,499 or 1,500-2,499). In such cases, we recorded the lowest number shown. Furthermore, we recorded the presence or absence of images of the predator and/or people involved in the attack.

We used the category "report content" with two possible levels: (a) "non-graphic," if no graphic/sensationalistic elements were present in the title, sub-heading and/or images, or (b) "graphic," if the report contained at least one graphic/sensationalistic element. Following Bombieri et al. (2018), we considered as graphic those titles and subtitles including words such as "horror," "horrific," "nightmare," "man-eating," "badly," "scary," "terrifying," "terrorizes," "blood," "bloody," "gruesome," "eaten," and "jaws," as well as explicit mention of the injured part of the body (e.g., "He's eating my brains', recalls bear attack survivor"). However, just specific mention of bodily injuries, e.g., "Man sustains leg injuries after alligator attack," was not considered graphic. We considered images, i.e., drawings, pictures or video, as being graphic if they (1) explicitly showed the predator's teeth and claws, (2) showed the attack, and/or (3) included details of injured body parts or people clearly displaying their injuries, as well as deceased individuals. Images of the animal in normal postures, such as a walking wolf, a sleeping leopard, a sunbathing alligator, a swimming shark, or a mother bear with cubs, were regarded as non-graphic. Some examples of graphic and non-graphic titles, subtitles, and images are presented in Figure 1.
We also collected information about the newspapers in which the reports were published, i.e., (1) name of the journal, (2) geographical area, and (3) type of distribution/audience, i.e., local, national or worldwide. We classified newspapers as local, national, or worldwide on the basis of the World Press Trends 2016 Report (Milosevic, 2016) and cross-checking this on the newspapers' webpage. On the basis of the distribution range of the predator species under study, we classified newspaper geographical areas (i.e., publication area of the newspaper), defining the following regions: Europe, Asia, Africa, North America (USA and Canada), Central/South America, Oceania; the Arctic (i.e., Greenland and Svalbard) and Russia were merged and considered as a single geographical area named "Russia + Arctic." Some reports were published in newspapers (e.g., LiveLeak, The Conversation, USA Today) which did not belong to a specific area and, therefore, we have included them in an additional category called "undefined." We use the same defined areas to classify large carnivore attack distribution, i.e., where the attack occurred (Figure 2).

\section{Data Analysis}

To determine how media reports of predator attacks on humans spread on SM, a statistical hypothesis testing framework was adopted. The null hypothesis was that there was no association between NTS and: (i) the "report content" (i.e., graphic or nongraphic), (ii) the presence or absence of images, (iii) the species considered, and (iv) the newspaper coverage (i.e., local, national or worldwide). We modeled the NTS by specifying a Poisson error distribution and a log link function. Since all initial models were highly over-dispersed (Over-dispersion statistics > 5,000; Zuur et al., 2009), we set a negative binomial error distribution model and included newspaper area as a random effect.

Because the presence or absence of images and report content were highly and positively correlated $\left(\operatorname{Pr}(>|z|)=2.84 \mathrm{e}^{-8}\right)$ as were species and report content (Logistic GLM, Type II Wald Chi Squared Test: Species $\chi_{12}^{2}=31.54, p=0.002$; Cox and Snell's pseudo $\mathrm{R}^{2}=0.079$ ), we built two different sets of negative binomial GLMMs. In the first set of models, we tested the effect of report content as well as that of newspaper type by including NTS as the response variable, the report content, newspaper type and their interaction as fixed factors, and newspaper area as a random factor. In the second set of models, we assessed whether the NTS varied with the presence or absence of images, among the species considered $(n=13)$ and newspaper type. Again, we included NTS as the response variable, presence or absence of images, species and newspaper type as fixed factors, while newspaper area was set as a random factor. The best competing model or set of models was chosen based on corrected Akaike criterion for finite sample size (AICc; Hurvich and Tsai, 1989). We considered as equally competitive those models with $\triangle \mathrm{AICc}$ $<2$ (Burnham and Anderson, 2002). Values of weighted AICc, indicating the probability that the model selected was the best among the competing candidates, were calculated as well. All analyses were performed in R 3.4.3 (R Core Team, 2017) using the package "glmmAMDB" (Fournier et al., 2012; Skaug et al., 2013) for model construction and the package "MuMIn" (Bartón, 2013) for model selection. 


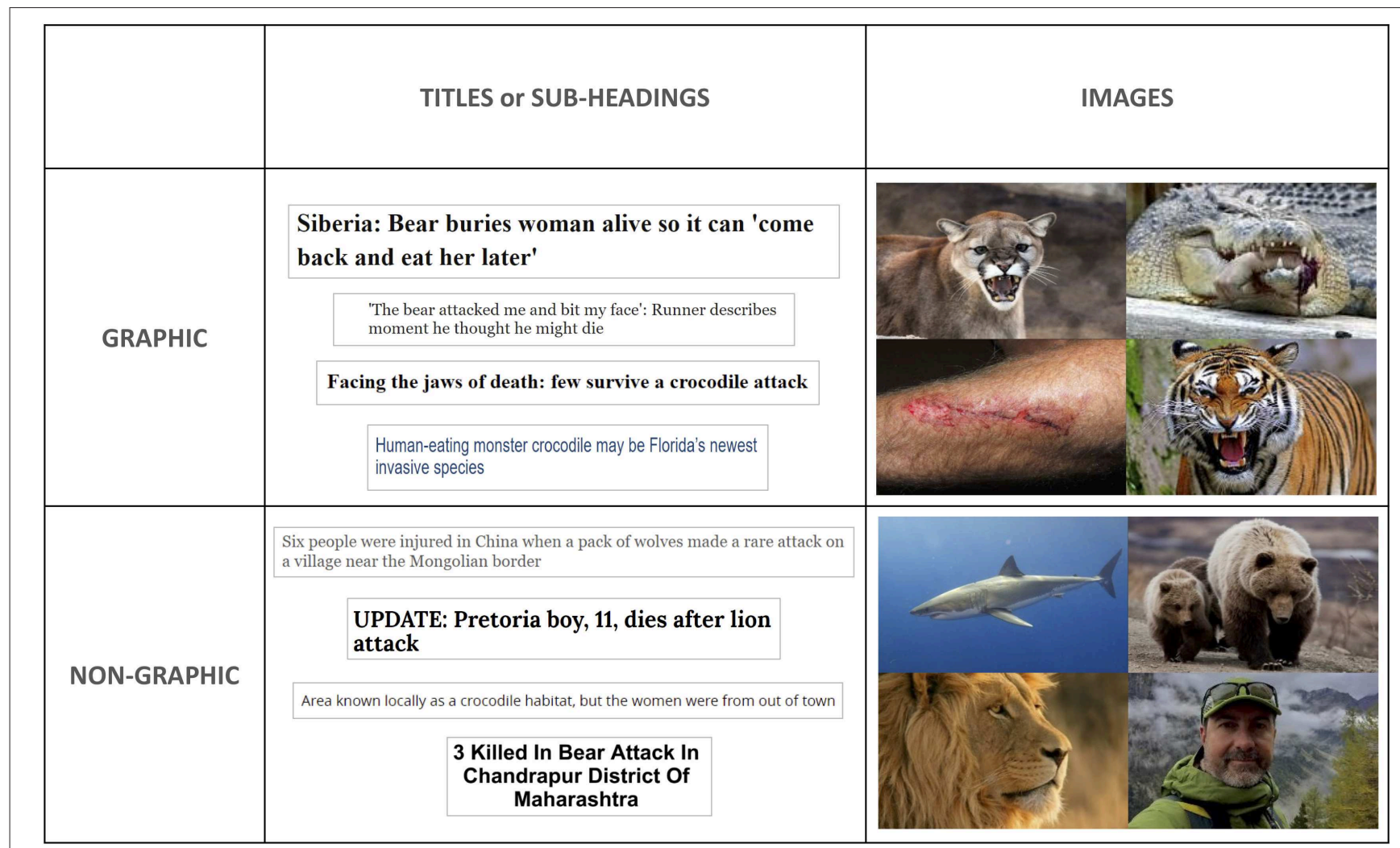

FIGURE 1 | Some examples of graphic vs. non-graphic titles or subtitles, as well as graphic vs. non-graphic images of predators/people involved in attacks, which were presented in the collected media reports. [Photo credits: Supplemental Table 2].

\section{RESULTS}

Out of the 1,774 collected reports, 429 displayed the NTS on their webpage. Such reports were published in 155 different online newspapers and the majority of them were published in national newspapers ( $49 \%, n=210)$, followed by local $(29.8 \%, n=128)$ and worldwide newspapers $(21.2 \%, n=91)$.

Most media reports were published in North American newspapers $(59 \%, n=253)$, followed by European $(19.6 \%, n=$ $84)$ and Asian $(14.7 \%, n=63)$ ones. A small portion came from African $(2.6 \%, n=11)$ and "Russian + Arctic" newspapers (2.1\%, $n=9)$. Only one report was published in an Oceanic newspaper whereas no reports were published in Central/South America (Figure 2B). For $1.9 \%$ of the reports $(n=8)$, geographical area was categorized as undefined. The scenario differs slightly when considering the geographical area in which the attacks occurred (Figure 2B), with European newspapers only reporting cases that took place in other parts of the world.

The reports mainly focused on brown bears $(16.1 \%, n=69)$ and leopards $(14.9 \%, n=64)$, followed by black bears $(12.4 \%, n=$ $53)$, alligators $(10.7 \%, n=46)$, crocodiles $(10.5 \%, n=45)$, sharks $(8.2 \%, n=35)$, coyotes $(7.2 \%, n=31)$, cougars $(5.8 \%, n=25)$, polar bears $(4.2 \%, n=18)$, lions $(3.7 \%, n=16)$, wolves $(2.8 \%, n$ $=12)$, tigers $(1.9 \%, n=8)$, and sloth bears $(1.6 \%, n=7)$. Nearly half of the reports included graphic elements $(43.1 \%, n=171)$. Images were present in $75.3 \%(n=323)$ of the reports.

In the first set of competing models, the model with the lowest AICc included only the variable report content (Table 1). Specifically, graphic reports were shared significantly more often on SM than non-graphic reports (Figure 3A), whereas newspaper type had no effect on the NTS (Figure 3B). However, national and worldwide newspaper reports were more shared if they included graphic content, while there was no difference in NTS between graphic and non-graphic reports at a local scale (Figure 3C).

In the second set of competing models, the model with the lowest AICc included the variables presence or absence of images and species (Table 2), i.e., the former variable played a major role in explaining the NTS, with reports containing images being shared more frequently than reports without them. In this model, species also had an important role in determining the NTS (Figure 4B, Table 2). Specifically, lion, shark, and alligator were the most frequently shared species (Figure 4B). For most of the species, graphic reports were more shared than non-graphic reports, but for other species, such as shark, black bear and alligator, the spread of graphic and non-graphic reports did not differ (Figure 4C). 

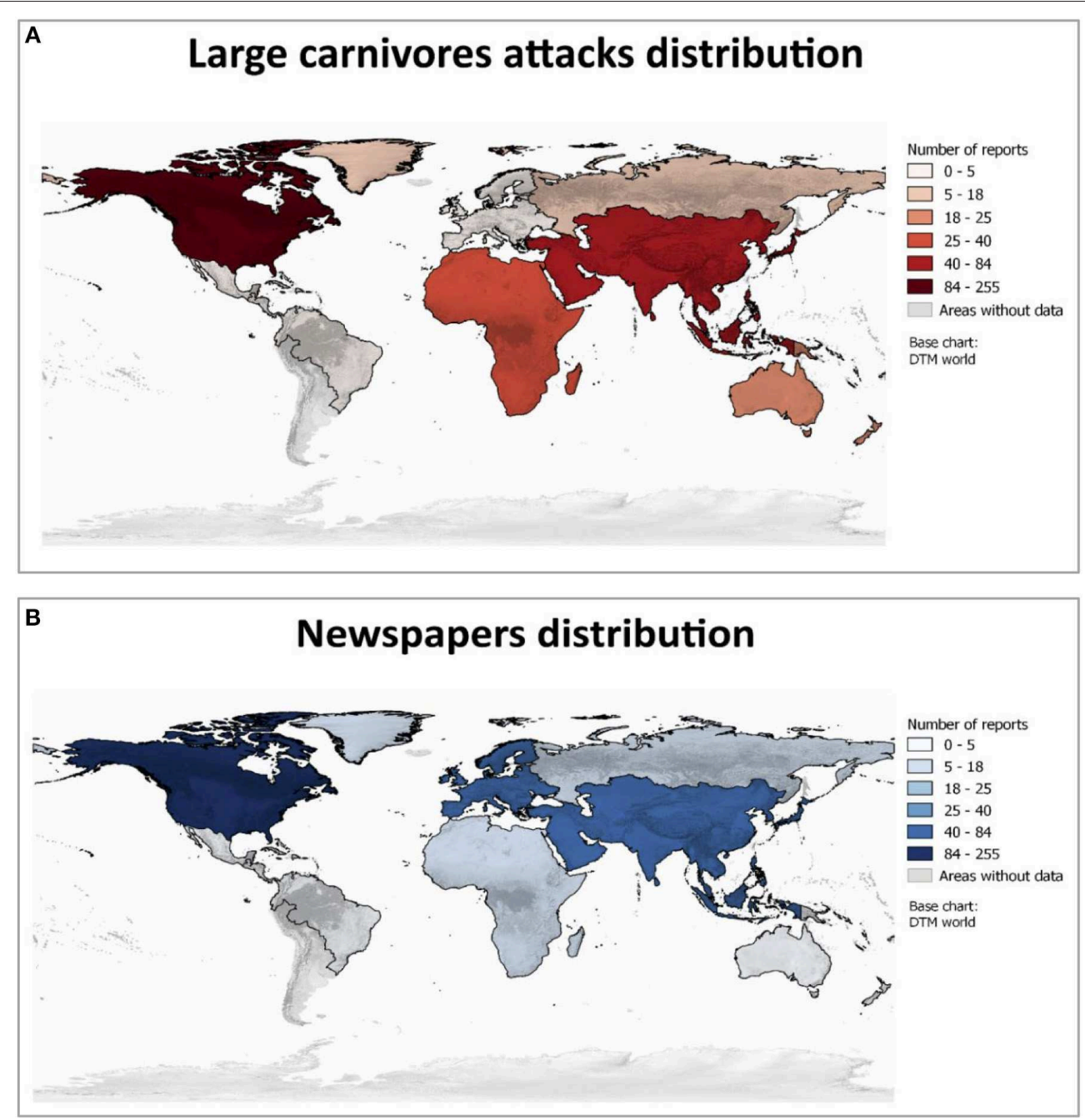

FIGURE 2 | Worldwide* overview of the distribution of the collected reports showing the geographical areas of: (A) large carnivore attacks on humans; and (B) the newspapers in which the reports were published. This information is shown for the subset of reports for which information on the number of shares on social media was available $(n=429)$. In Europe we can observe a difference between the two maps, which can be explained by the fact that reports published in European newspapers only described events that occurred in other parts of the world. Because the online research of reports describing large carnivore attacks on humans was conducted in the English language, the area of North America is overrepresented. *We had no report for Antarctica and for the southern part of South America (i.e., Bolivia, Paraguay, Uruguay, Chile, and Argentine) as well as for Iceland.

\section{DISCUSSION}

Our findings confirm that reports containing graphic elements were shared more frequently on SM than non-graphic ones (Figure 3A). Indeed, NTS for these sensationalistic reports is higher than for reports presenting facts more objectively, i.e., without adding sensationalistic components. Moreover, our results suggest that, when one or more images were present, reports were more frequently shared (Figure 4A). Thus, images are crucial in capturing the attention of readers, motivating them to share the news on SM.

We also found differences in NTS between species, which could reflect cultural and social factors. Specifically, lion, shark, and alligator were the most frequently shared species (Figure 4B), although shark and alligator did not show marked difference between the graphic and non-graphic diffusion of news (Figure 4C). Our findings show that reports about sharks and alligators seem to have great resonance regardless of the way in which the news was framed. This might be explained by a lower empathy for animal groups that are phylogenetically distant to humans (Ingham et al., 2015) and inhabit unfamiliar human environments (Bornatowski et al., 2019), where there is a deeprooted fear of these species (Campbell and Smith, 1993; Giblett, 2009). Conversely, a strong difference between graphic and nongraphic reports was shown for lion attacks, for which graphic reports were significantly more shared (Figure 4C). Moreover, the lion was the species with the highest NTS. This may be 
TABLE 1 | Comparison of the competing models built to analyze the influence of report content (i.e., graphic or non-graphic), and newspaper type (i.e., local, national or worldwide) on the diffusion of the reports on social media.

\begin{tabular}{|c|c|c|c|c|c|c|}
\hline Competing models & & Estimated $\beta \pm$ s.e. & p-value & $\mathrm{AlCc}$ & $\Delta \mathrm{AlCc}$ & Weighted AICc \\
\hline \multirow[t]{3}{*}{ Report content } & & & & 4948.89 & 0.00 & 0.53 \\
\hline & Intercept & $6.82 \pm 0.56$ & & & & \\
\hline & Report content ${ }^{a}$ & $-0.76 \pm 0.25$ & 0.002 & & & \\
\hline \multirow[t]{4}{*}{ Report content * type } & & & & 4949.62 & 0.73 & 0.37 \\
\hline & Intercept & $7.56 \pm 0.69$ & & & & \\
\hline & Report content ${ }^{a}{ }^{*}$ type ${ }^{b}$ & $1.42 \pm 0.60$ & 0.027 & & & \\
\hline & Report content ${ }^{a}{ }^{*} t_{y p e}{ }^{c}$ & $1.52 \pm 0.72$ & 0.036 & & & \\
\hline Report content + type & & & & 4952.56 & 3.66 & 0.09 \\
\hline Null model & & & & 4956.36 & 7.46 & 0.02 \\
\hline Type & & & & 4958.88 & 9.99 & 0.01 \\
\hline
\end{tabular}

${ }^{a}$ Reference category: graphic content.

bLevel: national.

${ }^{c}$ Level: worldwide.

Reports regarded attacks on humans by 13 different large carnivores around the world. Here, we considered report content, newspaper type, and their interaction as predictive variables. Competing model values of AICC, $\triangle A I C C$, and Weighted AICC are shown from the best (lowest AlCc value) to the worse model (highest AlCc value).
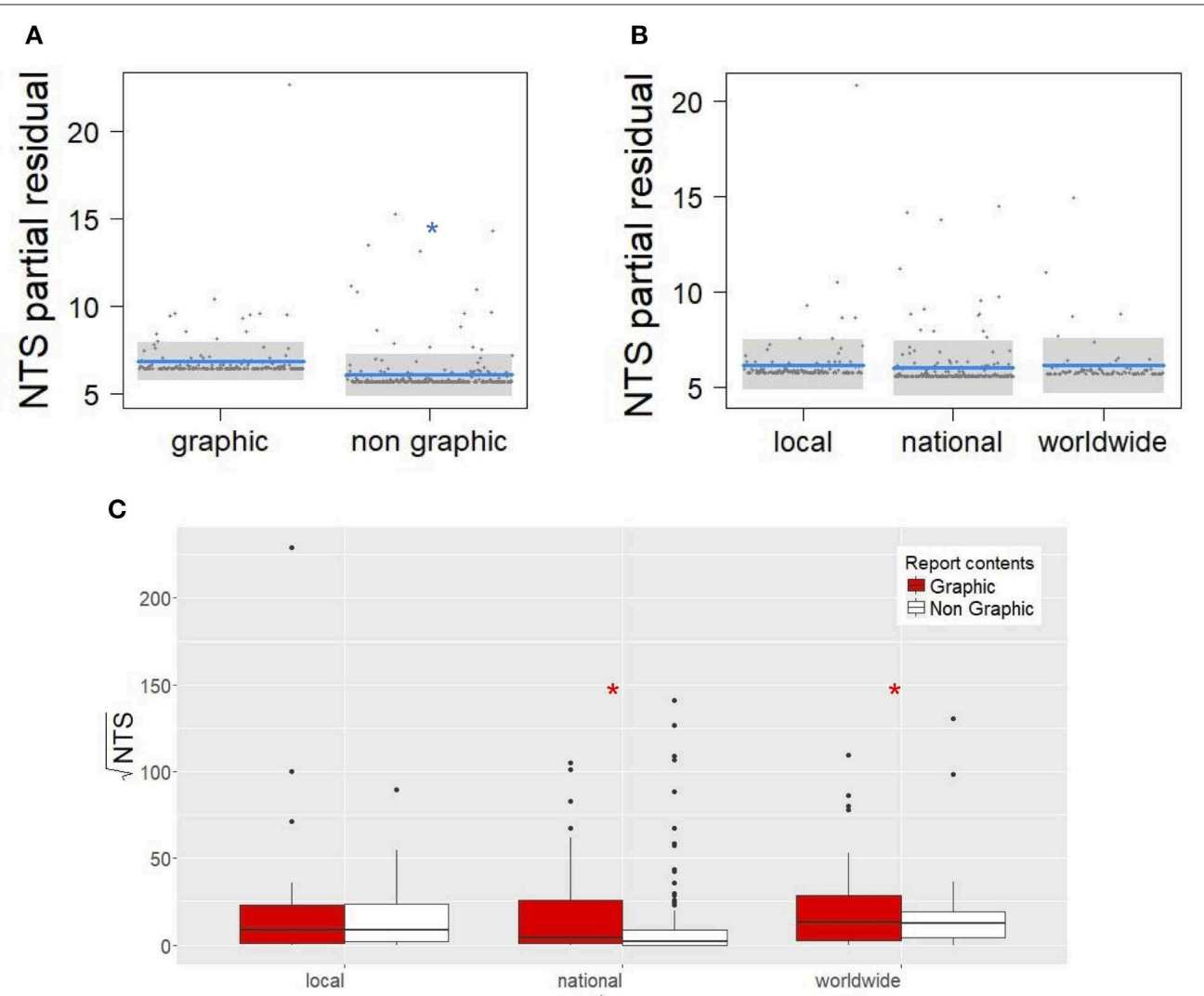

FIGURE 3 | Comparison between: (A) graphic and non-graphic reports; and (B) type of newspaper over the number of total shares (NTS) partial residuals. Graphic reports were significantly more shared than non-graphic ones $(p=0.002)$, whereas there were no significant differences between reports published in local, national or worldwide newspapers (local vs. national: $p=0.52$; local vs. worldwide: $p=0.76$; national vs. worldwide: $p=0.99$ ). The boxplots (C) show a comparison between graphic (red) and non-graphic (white) reports over the square rooted NTS for each type of distribution/audience. *Significant differences (exact estimated parameters and $p$-values are in Table 1).

due to not only the iconic value of this species, but also a possible artifact due to the small sample size of reports for lions $(n=16)$.
Interestingly, the type of newspaper did not affect the NTS. Indeed, this variable was always excluded in the first set of competitive models, and it had low importance in the second 
TABLE 2 | Comparison of the competing models built to analyze diffusion of the reports on social media regarding attacks on humans by 13 different large carnivores around the world.

\begin{tabular}{|c|c|c|c|c|c|}
\hline $\begin{array}{l}\text { Competing } \\
\text { Models }\end{array}$ & Estimated $\beta \pm$ s.e. & $p$-value & $\mathrm{AICc}$ & $\Delta \mathrm{AICc}$ & $\begin{array}{c}\text { Weighted } \\
\text { AICc }\end{array}$ \\
\hline Images + species & & & 4918.74 & 0.00 & 0.52 \\
\hline Intercept & $5.68 \pm 0.36$ & & & & \\
\hline Image presence & $2.28 \pm 0.32$ & $1.6 e^{-12}$ & & & \\
\hline Black bear & $-1.02 \pm 0.50$ & 0.04073 & & & \\
\hline Cougar & $-1.67 \pm 0.60$ & 0.00503 & & & \\
\hline Coyote & $-1.52 \pm 0.58$ & 0.00931 & & & \\
\hline Crocodile & $-1.74 \pm 0.49$ & 0.00039 & & & \\
\hline Brown bear & $-0.91 \pm 0.49$ & 0.06073 & & & \\
\hline Leopard & $-2.39 \pm 0.49$ & $9.4 e^{-07}$ & & & \\
\hline Lion & $0.11 \pm 0.71$ & 0.87394 & & & \\
\hline Polar bear & $-2.26 \pm 0.66$ & 0.00056 & & & \\
\hline Shark & $-0.25 \pm 0.57$ & 0.66073 & & & \\
\hline Sloth bear & $-1.04 \pm 0.97$ & 0.28395 & & & \\
\hline Tiger & $-1.19 \pm 0.92$ & 0.19834 & & & \\
\hline Wolf & $-2.02 \pm 0.76$ & 0.00778 & & & \\
\hline $\begin{array}{l}\text { Images + species } \\
+ \text { type }\end{array}$ & & & 4918.51 & 0.17 & 0.48 \\
\hline Images & & & 4931.39 & 13.05 & 0.00 \\
\hline Images + type & & & 4933.46 & 15.12 & 0.00 \\
\hline Species & & & 4947.34 & 29.00 & 0.00 \\
\hline Species + type & & & 4950.85 & 32.51 & 0.00 \\
\hline Null model & & & 4955.96 & 37.62 & 0.00 \\
\hline Type & & & 4958.48 & 40.14 & 0.00 \\
\hline
\end{tabular}

Here, we considered presence or absence of images, species and newspaper type as predictive variables. Competing models values of AICC, $\triangle A / C C$ and Weighted AICC are shown from the best (lowest AlCC value) to the worse model (highest AICc value).

set (Table 2), suggesting that newspaper visibility does not necessarily influence the spread of news on SM. Instead, even those events that are only covered by local newspapers can spread widely on SM, indicating that, regardless of the source, SM has the power to disseminate information at a global scale. Even though the NTS was roughly the same at the three scales considered (Figure 3B), at national and worldwide scales it was significantly higher for graphic reports (Figure 3C). The fact that local reports are more commonly read by local readers (Takhteyev et al., 2012), might suggest that living in proximity of the attack occurrence will more likely induce a reader to share the attack news on SM, regardless of its graphic or non-graphic content. Conversely, at a broader scale (i.e., national or worldwide), only a news report that contains explicit graphic content is likely to upset a distant reader, thus inducing them to share it on SM.

We conducted the online reports search in English, since this is the most common spoken language worldwide. However, this might lead to a bias in NTS, because in geographical areas where English is not widely spoken, English language articles might receive less attention (lower NTS). Future studies could extend this approach and include media reports published in other widely spoken languages, such as Spanish or Chinese. It is also worth noting that our study design did not allow distinguishing between the underlying motivations of each individual share event on SM. Indeed, we had no access to the content of individual posts on SM but only to the number of total shares (NTS) available in the newspaper's webpage. Therefore, whereas we treated all SM sharing about a news article as being in agreement with the article's message, some readers may also share news with the intent of criticizing its content as being inaccurate or sensationalistic.

The Internet and SM are emerging as influential news reference sources, where people inform themselves, learn, and form their perception of the world, becoming major drivers in shaping public opinion. Graphic reports represent a considerable percentage $(43.1 \%)$ of the total of shared reports, and they were also the most frequently shared reports on SM, suggesting that people are potentially being flooded by content that heightens their anxieties and fears. Furthermore, the use of violent and disturbing texts and/or images increases the likelihood that an event remains imprinted in our memory (Harrell, 2000). This, in turn, negatively conditions our perception of risk (Myers, 2004), especially if accompanied by visual communications (Harrell, 2000). This bias in exposure to graphic and sensationalistic content can generate unwarranted fear and prejudice against predators, increasing human-large carnivore conflicts and, consequently, lowering public support for predator conservation policies.

Humans have an instinctive fear of large carnivores (Kruuk, 2002), and such a negative attitude may be reinforced by news media presentations (Bombieri et al., 2018) and their spread on SM. Even if attacks provoked by large carnivores have been rising in the last few decades, they still remain rare events (Penteriani et al., 2016) and the probability of having an encounter is very low, making the concern they raise disproportionate.

According to our results, the information that is spread on SM is biased toward a graphic and sensationalistic view of predators. Indeed, SM is driving social amplification of the perceived risk and lower public tolerance for predators, thus potentially affecting large carnivore conservation and management efforts. This is consistent with the large body of experimental research showing that media attention is negatively skewed toward negative events (e.g., Trussler and Soroka, 2014), even despite survey evidence which suggests that the general public does not enjoy negatively framed news (e.g., West, 2001). The psychology of impression formation has shown that individuals seem to have a propensity to weigh negative information more heavily than positive information (e.g., Vonk, 1996), possibly for evolutionarily processes, for which it might be advantageous to prioritize negative over positive information (Soroka, 2014). Since humans tend to be mildly optimistic, negative information is further away from their expectations than is positive information. In turn, this makes negative information more aberrant and consequently more useful and interesting (e.g., Skowronski and Carlston, 1989), and thus media content may simply reflect this tendency. 


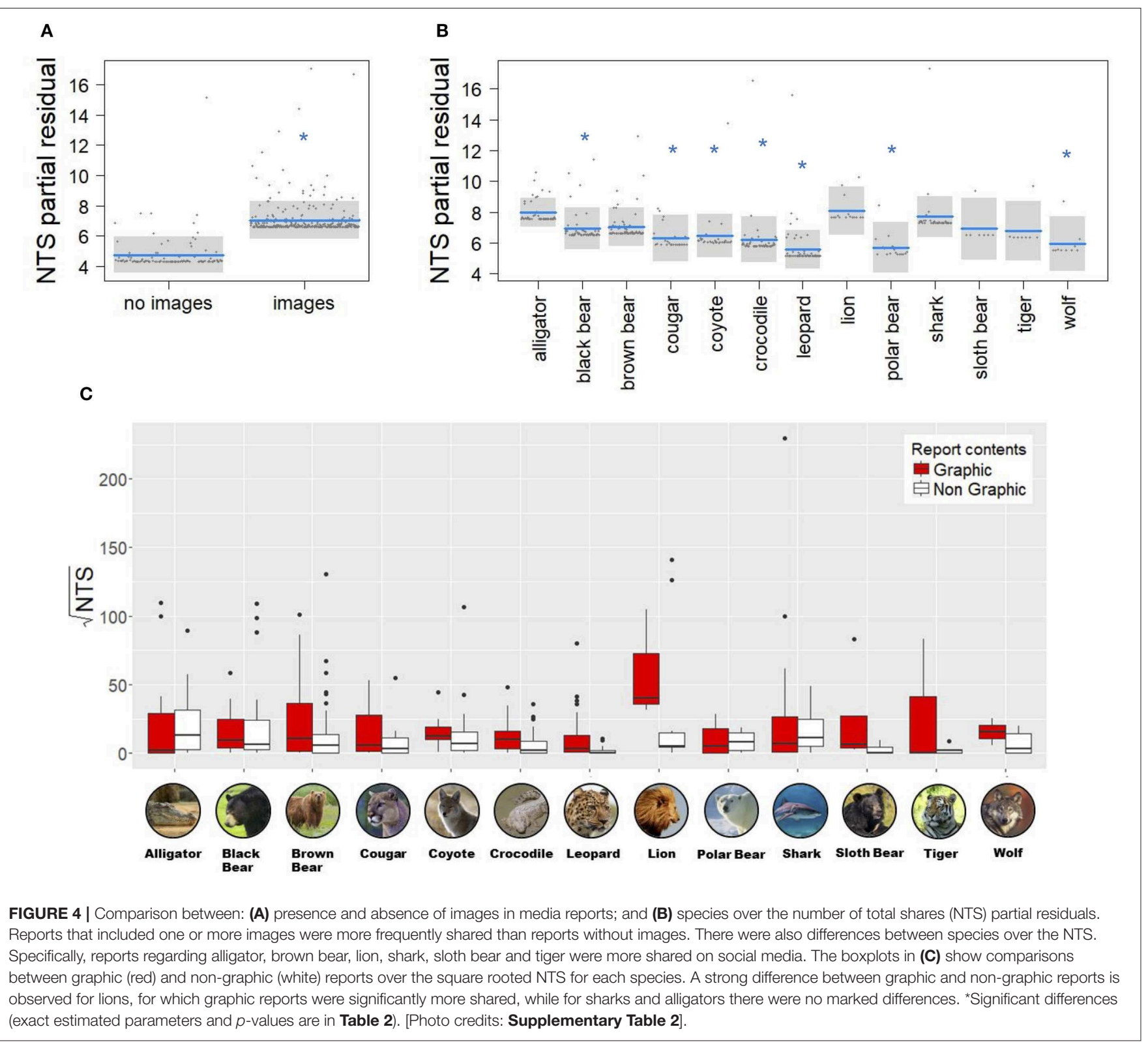

However, because SM represents a powerful communication tool, its role may change if used appropriately. Constant engagement of scientists on SM may contribute to both disseminate more accurate information on large carnivores and stem the tide of misinformation before its widespread diffusion, a crucial step for effective predator conservation. As a consequence, potential strategies to improve human coexistence with predators need to include the use of SM to increase public support for conservation actions. Precisely because of its great ability to reach the public, SM offers opportunities for easy exchange and connectivity between scientists and the public (Papworth et al., 2015), not just for the fast circulation of messages, but also to grab the attention of people that rely on SM to keep themselves informed of recent events. Papworth et al. (2015) stated that the news media is the fourth sector in the conservation process, together with scientists, policy makers, and the public. By highlighting the tendency of SM to filter and spread news reports that dramatize attack events by using graphic content, we argue that, among all the media and communication tools, SM is probably the most powerful and, as such, it should be proactively employed by scientists and conservationists as their main tool to share and spread accurate information to the public at large.

\section{DATA AVAILABILITY STATEMENT}

All datasets generated for this study are included in the Supplementary Table 1. 


\section{ETHICS STATEMENT}

Written informed consent was obtained from the individual(s) for the publication of any potentially identifiable images or data included in this article.

\section{AUTHOR CONTRIBUTIONS}

$\mathrm{VN}$ and EC initiated and conceived the study. VN, VP, and $\mathrm{GB}$ collected online reports. VN implemented and prepared the final dataset. VN and EC performed the statistical analysis and prepared the figures with the help of SM. VN wrote the manuscript with the help of GB, VP, CC, EC, and SM. EC, GB, SS, CC, SM, PP, and VP commented on the manuscript draft.

\section{FUNDING}

VP was financially supported by the Excellence Project CGL2017-82782-P financed by the Spanish Ministry of Science, Innovation and Universities, the Agencia Estatal de Investigación (AEI) and the Fondo Europeo de Desarrollo Regional (FEDER, EU). VP was also funded by a GRUPIN research grant from the Regional Government of Asturias (Ref.: IDI/2018/000151). GB was financially supported by a

\section{REFERENCES}

Altheide, D. L. (1997). The news media, the Problem frame, and the production of fear. Soc. Q. 38, 647-668. doi: 10.1111/j.1533-8525.1997.tb00758.x

An, J., Cha, M., Gummadi, K., and Crowcroft, J. (2011). "Media landscape in twitter: a world of new conventions and political diversity," in Proceedings of the Fifth International AAAI Conference on Weblogs and Social Media. (Barcelona), 623-628.

Bartón, K. (2013). Model Selection and Model Averaging Based on Information Criteria (AICc and alike). The Comprehensive R Archive Network 1:13. Available online at: https://cran.r-project.org/web/packages/MuMIn/index.html

Berger, J. A., and Milkman, K. L. (2012). What makes online content viral? J. Market. Res. 4, 192-205. doi: 10.1509/jmr.10.0353

Bombieri, G., Nanni, V., del Mar Delgado, M., Fedriani, J. M., López-Bao, J. V., Pedrini, P., et al. (2018). Content analysis of media reports on predator attacks on humans: toward an understanding of human risk perception and predator acceptance. BioScience 68, 577-584. doi: 10.1093/biosci/ biy072

Bornatowski, H., Hussey, N. E., Sampaio, C. L. S., and Barreto, R. R. P. (2019). Geographic bias in the media reporting of aquatic versus terrestrial human predator conflicts and its conservation implications. Perspect. Ecol. Conserv. 7, 32-35. doi: 10.1016/j.pecon.2018.12.004

Bösch, K., Müller, O., and Schneider, J. (2018). "Emotional contagion through social network," in 26th European Conference on Information Systems: Beyond Digitization - Facets of Socio-Technical Change, ECIS, 11-28.

Burnham, K. P., and Anderson, D. R. (2002). Model Selection and Multimodel Inference: A Practical Information-Theore- Tic Approach. New York, NY: Springer-Verlag.

Campbell, G. D., and Smith, E. D. (1993). The 'problem' of shark attacks upon humans. J. Wilderness Med. 4, 5-10. doi: 10.1580/0953-9859-4.1.5

Couldry, N. (2012). Media, Society, World: Social Theory and Digital Media Practice. Cambridge, UK: Polity Press.

Decker, D. J., Lauber, T. B., and Siemer, W. F. (2002). Human-Wildlife Conflict Management: A Practitioner's Guide. Ithaca, NY: Northeast Wildlife Damage Management Research and Outreach Cooperative.

Farhi, P. (2009). The twitter explosion. Am. J. Rev. 31, 1-6. collaboration contract with the MUSE-Museo delle Scienze of Trento (Italy).

\section{ACKNOWLEDGMENTS}

We would like to thank Chiara Bettega, Massimo Pettavino, and Giulia Dapueto for their advice regarding GIS maps. Thanks to Giorgio Matricardi and Luisa Stagi who were a link between the team of multidisciplinary co-authors. VN would like to thank all teachers and professors who have arouse her curiosity. We are also grateful to the editor and the reviewers whose valuable comments improved the quality of the manuscript.

\section{SUPPLEMENTARY MATERIAL}

The Supplementary Material for this article can be found online at: https://www.frontiersin.org/articles/10.3389/fevo. 2020.00071/full\#supplementary-material

Supplementary Table 1 | Dataset used for the analyses. The dataset includes information and the total number of shares (NTS) of the news reports collected from international newspapers between 2005 and 2017.

Supplementary Table 2 | License information regarding the photos used in Figures 1, 4. Credits, types of license and other details are specified for each of the photos used.
Ferrara, E., and Yang, Z. (2015). Measuring emotional contagion in social media. PLoS ONE 10:e0142390. doi: 10.1371/journal.pone.0142390

Fournier, D. A., Skaug, H. J., Ancheta, J., Ianelli, J., Magnusson, A., Maunder, M. N., et al. (2012). AD model builder: using automatic differentiation for statistical inference of highly parameterized complex nonlinear models. Optim. Methods Softw. 27, 233-249. doi: 10.1080/10556788.2011.597854

Giblett, R. (2009). Alligators, Crocodiles and the Monstrous Uncanny. Landscapes of Culture and Nature. London: Palgrave Macmillan, 17-35.

Harrell, J. P. (2000). Affective Responses to Television Newscasts: Have You Heard The News? Western Michigan University. Available online at: http://ovidsp. ovid.com/ovidweb.cgi? $\mathrm{T}=\mathrm{JS} \& \mathrm{PAGE}=$ reference $\& \mathrm{D}=\mathrm{psyc} 3 \& \mathrm{NEWS}=\mathrm{N} \& \mathrm{AN}=$ 2000-95022-294.

Hermida, A., Fletcher, F., Korell, D., and Logan, D. (2012). SHARE, LIKE, RECOMMEND: decoding the social media news consumer. J. Stud. 13, 815-824. doi: 10.1080/1461670X.2012.664430

Hurvich, C. M., and Tsai, C.-L. (1989). Regression and time series model selection in small samples. Biometrika 76, 297-307. doi: 10.1093/biomet/76.2.297

Ingham, H. R. W., Neumann, D. L., and Waters, A. M. (2015). Empathyrelated ratings to still images of human and nonhuman animal groups in negative contexts graded for phylogenetic similarity. Anthrozoos 28, 113-130. doi: 10.2752/089279315X14129350722136

Ju, A., Jeong, S. H., and Chyi, H. I. (2014). Will social media save newspapers? examining the effectiveness of facebook and twitter as news platforms. J. Pract. 8, 1-17. doi: 10.1080/17512786.2013.794022

Kasperson, R. E., and Kasperson, J. X. (1996). The social amplification and attenuation of risk. Ann. Am. Acad. Pol. Soc. Sci. 545, 95-105. doi: $10.1177 / 0002716296545001010$

Kietzmann, J. H., Hermkens, K., McCarthy, I. P., and Silvestre, B. S. (2011). Social media? Get serious! understanding the functional building blocks of social media. Bus. Horiz. 54, 241-251. doi: 10.1016/j.bushor.2011.01.005

Knopff, A. A., Knopff, K. H., and St. Clair, C. C. (2016). Tolerance for cougars diminished by high perception of risk. Ecol. Soc. 21:33. doi: 10.5751/ES-08933-210433

Kramer, A. D. I., Guillory, J. E., and Hancock, J. T. (2014). Experimental evidence of massive-scale emotional contagion through social networks. Proc. Natl Acad Sci U.S.A. 111, 8788-8790. doi: 10.1073/pnas.1320040111 
Kruuk, H. (ed.). (2002). Hunter and Hunted, Relationships between Carnivores and People. Cambridge: Cambridge University Press. doi: 10.1017/CBO9780511614996

Lee, C. S., and Ma, L. (2012). News sharing in social media: the effect of gratifications and prior experience. Comput. Hum. Behav. 28, 331-339. doi: 10.1016/j.chb.2011.10.002

Milosevic, M. (2016). World Press Trends 2016. Page Wan Ifra. Available online at: https://en.wikipedia.org/wiki/List_of_newspapers_by_circulation

Myers, D. G. (2004). Do We Fear The Right Things? American Psychological Society Observer. Available online at: http://www.psychologicalscience.org/observer/ 1201/prescol.html.

Nov, O., Naaman, M., and Ye, C. (2010). Analysis of participation in an online photo-sharing community: a multidimensional perspective. J. Am. Soc. Inform. Sci. Technol. 61, 555-566. doi: 10.1002/asi.21278

Olmstead, K., Mitchell, A., and Rosenstiel, T. (2011). Navigating News Online: Where People Go, How They Get There and What Lures Them Away. Pew Research Center, 1-30. Available online at: http://www.journalism.org/files/ legacy/NIELSENSTUDY-Copy.pdf

Osatuyi, B. (2013). Information sharing on social media sites. Comput. Hum. Behav. 29, 2622-2631. doi: 10.1016/j.chb.2013.07.001

Papworth, S. K., Nghiem, T. P. L., Chimalakonda, D., Posa, M. R. C., Wijedasa, L. S., Bickford, D., et al. (2015). Quantifying the role of online news in linking conservation research to facebook and twitter. Conserv. Biol. 29, 825-833. doi: 10.1111/cobi.12455

Penteriani, V., del Mar Delgado, M., Pinchera, F., Naves, J., Fernández-Gil, A., Kojola, I., et al. (2016). Human behaviour can trigger large carnivore attacks in developed countries. Sci. Rep. 6:20552. doi: 10.1038/srep20552

Purcell, K., Rainie, L., Mitchell, A., Rosenstiel, T., and Olmstead, K. (2010). Understanding The Participatory News Consumer: How Internet And Cell Phone Users Have Turned News into a Social Experience. Pew Research Center. 1-63.

R Core Team (2017). R: A Language and Environment for Statistical Computing. Vienna: R Foundation for Statistical Computing. Available online at: https:// www.r-project.org/.

Ripple, W. J., Estes, J. A., Beschta, R. L., Wilmers, C. C., Ritchie, E. G., Hebblewhite, M., et al. (2014). Status and ecological effects of the world's largest carnivores. Science 343:1241484. doi: 10.1126/science.1241484

Rutsaert, P., Regan, Á., Pieniak, Z., McConnon, Á., Moss, A., Wall, P., et al. (2013). The use of social media in food risk and benefit communication. Trends Food Sci. Technol. 30, 84-91. doi: 10.1016/j.tifs.2012.10.006

Schafer, N. P. (2011). Dismantling media produced fear toward predators (Master's thesis), University of Otago, Dunedin, New Zealand.

Skaug, H., Fournier, D., Nielsen, A., Magnusson, A., and Bolker, B. (2013). Generalized Linear Mixed Models Using AD Model Builder. R package version 0.77. Available online at: http://glmmadmb.r-forge.r-project.org/
Skowronski, J. J., and Carlston, D. E. (1989). Negativity and extremity biases in impression formation : a review of explanations. Psychol. Bull. 105:131. doi: 10.1037/0033-2909.105.1.131

Soroka, S. N. (2014). Negativity in Democratic Politics Causes and Consequences. Cambridge, UK: Cambridge University Press. doi: 10.1017/CBO9781107477971

Stieglitz, S., and Dang-Xuan, L. (2013). Emotions and information diffusion in social media-sentiment of microblogs and sharing behavior. J. Manage. Inform. Syst. 29, 217-248. doi: 10.2753/MIS0742-1222 290408

Sunstein, C. R. (2002). The laws of fear. Harvard Law Rev. 115, 1119-1168. doi: $10.2307 / 1342630$

Szabo, G., and Huberman, B. A. (2010). Predicting the popularity of online content. Comun. ACM 53, 80-88. doi: 10.1145/1787234.1787254

Takhteyev, Y., Gruzd, A., and Wellman, B. (2012). Geography of Twitter networks. Soc. Netw. 34, 73-81. doi: 10.1016/j.socnet.2011.05.006

Trussler, M., and Soroka, S. (2014). Consumer demand for cynical and negative news frames. Int. J. Press/Polit. 19, 360-379. doi: 10.1177/1940161214524832

Vonk, R. (1996). Negativity and potency effects in impression formation. Euro. J.Soc. Psychol. 26, 851-865. doi: 10.1002/(SICI)10990992(199611)26:6<851::AID-EJSP790>3.0.CO;2-9

West, D. (2001). The Rise and Fall of the Media Establishment. New York, NY. doi: 10.1007/978-1-137-07405-8

Wu, Y., Xie, L., Huang, S., Li, P., Yuan, Z., and Liu, W. (2018). Using social media to strengthen public awareness of wildlife conservation. Ocean Coast. Manage. 153, 76-83. doi: 10.1016/j.ocecoaman.2017.12.010

Zillmann, D., Chen, L., Knobloch, S., and Callison, C. (2004). Effects of lead framing on selective exposure to internet news reports. Commun. Res. 31, 58-81. doi: 10.1177/0093650203260201

Zuur, A. F., Ieno, E. N., Walker, N. J., Saveliev, A. A., and Smith, G. M. (2009). Mixed Effects Models and Extension in R. Berlin: Springer. doi: 10.1007/978-0-387-87458-6

Conflict of Interest: The authors declare that the research was conducted in the absence of any commercial or financial relationships that could be construed as a potential conflict of interest.

Copyright (C) 2020 Nanni, Caprio, Bombieri, Schiaparelli, Chiorri, Mammola, Pedrini and Penteriani. This is an open-access article distributed under the terms of the Creative Commons Attribution License (CC BY). The use, distribution or reproduction in other forums is permitted, provided the original author $(s)$ and the copyright owner(s) are credited and that the original publication in this journal is cited, in accordance with accepted academic practice. No use, distribution or reproduction is permitted which does not comply with these terms. 